\title{
Response Rate of Cisplatin Plus Docetaxel as Primary Treatment in Locally Advanced Head and Neck Carcinoma (Squamous Cell Types)
}

\author{
Maryum Nouman*, Ghulam Haider, Neelma Bukhari, Aveen Yousuf, Rabeea \\ Nouman, Mehwish Roshan Shaikh, Shahid Hussain, Bhunisha Pavan, Raja \\ Rahool, Paras Memon, Saima Zahoor, Khalil Mehar, Abdus Sami
}

\begin{abstract}
Objective: To evaluate the response rate of Cisplatin plus Docetaxel in the treatment of locally advanced head and neck squamous cell carcinomas (HNSCC) at a tertiary care hospital in Karachi, Pakistan. Materials and Methods: It was a longitudinal study, conducted at the Department of Medical Oncology, Jinnah Postgraduate Medical Center, Karachi, Pakistan from December 2018 to June 2019. One hundred patients of age 14-66 years of age of either gender with histologically proven Squamous Cell Carcinoma of Head and Neck, Stage III and IV (locally advanced) with no distant metastases were included in the study. Patients who were declared unresectable by the otolaryngologist and those with delayed appointment for radiation were given 3 cycles of Induction Chemotherapy with Cisplatin and Docetaxel, both at a dose of $75 \mathrm{mg} / \mathrm{m}^{2} 3$ weekly. After 3 cycles, CT scan was repeated to assess the clinical response. Those patients who had partial or complete response as per RECIST criteria were re-assessed by the otolaryngologist and were planned for surgery if disease became resectable while other patients were referred for Concurrent ChemoRadiation Therapy (CCRT). SPSS version 23 was used to analyze data. Results: The partial response was achieved in majority of the patients after Induction Chemotherapy with Docetaxel and Cisplatin (62\%) with a complete response in $12 \%$. However, $22 \%$ showed progression of the disease, and $4 \%$ showed stable disease. The most frequent side effects observed were diarrhea (62\%) and neutropenia (57\%). Conclusion: Induction chemotherapy with Cisplatin and Docetaxel is a promising regimen with good response and favorable toxicity profile and can be considered as a potentially effective outpatient regimen for locally advanced squamous cell carcinoma of head and neck.
\end{abstract}

Keywords: Induction chemotherapy- Docetaxel- cisplatin- locally advanced head and neck carcinoma- response rate

Asian Pac J Cancer Prev, 21 (3), 825-830

\section{Introduction}

Around the globe head and neck carcinomas (HNCs) is the $6^{\text {th }}$ most common cancer with the incidence of 650,000 cases and 330,000 cases of mortality yearly (Bray et al., 2018). HNCs are mainly seen in men, but the man-to-woman ratio differs globally and by anatomical site with a ratio fluctuating from 2:1 to 4:1 (Lambert et al., 2011; Bray et al., 2013). Most of the HNCs appear in the epithelium of oral cavity, larynx, oropharynx and hypopharynx (Jemal et al., 2007; Boyle and Levin, 2008).

The overall 5 year survival rate of $\mathrm{HNCs}$ patients is estimated as 40-50\% (Kozakiewicz and Grzybowska-Szatkowska, 2018). Early stages (stage I and II) of HNCs showed favorable prognosis with increased cure rates of more than 70-90\% (Hashibe et al., 2009; Fung and Grandis, 2010) with surgery and radiotherapy alone (WHO, 2014). The patients with locally advanced stage of HNCs (stage III and IV) have been treated with multimodality therapy. In these advanced stages, surgery along with chemoradiotherapy or radiotherapy have been given to the patients for the treatment which depends upon the grade, histology or metastases of tumor in the regional lymph nodes (Adelstein et al., 2017; Brierley et al., 2017). In the meta-analysis, concurrent chemoradiotherapy (CCRT) has showed significant outcome of chemotherapy plus radiation, which gives an absolute of $8 \%$ survival benefit at 5 years in HNCs patients (Pignon et al., 2000). Thus CCRT has been considered as standard therapy for locally advanced HNCs but it has complications such as dermatitis, dysphagia and mucositis. CCRT has also increased the odds of bleeding or infection and frequently accompanied by thrombocytopenia and leukopenia (Andresen et al., 2006; Fung and Grandis, 
2010; Kozakiewicz and Grzybowska-Szatkowska, 2018).

The role of Induction Chemotherapy (ICT) remains investigational despite tremendous research. For patients with locally advanced squamous cell carcinoma of the head and neck (HNSCC), rapid advancements regarding the choice of induction chemotherapy regimen have been made. There is substantial evidence related to the advantage and superiority of three-drug combination of Docetaxel, Cisplatin, and Fluorouracil (TPF) over the doublet regime of Cisplatin and Fluorouracil (PF) used previously as ICT. docetaxel has shown promising results in recurrent and incurable cases of $\mathrm{HNCs}$ (Catimel et al., 1994; Dreyfuss et al., 1996). docetaxel has a longer intracellular half-life, greater affinity for tubulin and promotes microtube stabilization at lower drug concentrations. Docetaxel has distinctive chemical mechanism of action which helps in inducing the mitotic block in proliferating cells (Lavelle et al., 1995; Posner and Lefebvre, 2003). In the clinical trials of phase I and II docetaxel plus cisplatin or fluorouracil (5-FU) for the treatment of locally advanced squamous-cell HNCs, showed prolonged survival and high clinical and pathological response rates (Colevas et al., 2000; Tubiana-Mathieu et al., 2000). In the clinical trials by Colevas et al. and Tubiana et al. of docetaxel with 5-FU showed over all response rates of 24-27\% (Colevas et al., 2000; Tubiana-Mathieu et al., 2000). Whereas in the clinical trials of docetaxel with cisplatin, the overall response rates were reported as $33-76 \%$ and appeared to be more efficacious combination (Kienzer et al., 1998; Schoffski et al., 1999; Specht et al., 2000; Glisson et al., 2002).

The aim of our study was to evaluate the response rate of cisplatin plus docetaxel as Induction chemotherapy in the treatment of locally advanced HNCs (squamous cell types). This study will help in improving the functional outcomes and cure rates and integration of cisplatin with docetaxel as the potential agents of chemotherapy however this approach might be helpful in both resectable and unresectable HNCs patients.

\section{Materials and Methods}

It was a longitudinal study, conducted at the department of Medical oncology of Jinnah Postgraduate medical Center from Sept 2018 to Apr 2019. The sample size was estimated using Open Epi online sample size calculator by taking statistics for complete response as $13 \%$ in patients of locally advanced squamous cell carcinoma of head and neck treated with docetaxel (Dreyfuss et al., 1996), margin of error as $6.6 \%$ and $95 \%$ confidence interval, the calculated sample size came out as 100 . Non-probability consecutive sampling technique was employed for sample selection. The patients of age 14-66 years of either gender with histological proven squamous cell carcinoma of head and neck of locally advanced stage III and IV with no distant metastases were included in the study. Patients with previous history of chemotherapy and radiotherapy, Eastern Cooperative Oncology Group (ECOG) performance status of 3, known hypersensitivity to drugs, ischemic heart disease, cirrhosis and bleeding tendency were excluded from the study.

The ethical review committee approval was sought before the conduct of study. Informed written and verbal consent was taken from all the patients. Information regarding socio-demographic and clinical factors were obtained from all the patients. Clinically the initial stage of tumor was assessed on CT scan. Patients with locally advanced disease rendered inoperable by otolaryngologist and those whose radiation appointment was very late were given 3 cycles of induction chemotherapy with docetaxel and cisplatin both at a dose of $75 \mathrm{mg} / \mathrm{m}^{2} 3$ weekly. After 3 cycles the CT scan was repeated to assess the clinical response. Those patients who had partial or complete response were re-assessed by otolaryngologist and were planned for surgery if disease became resectable while other patients were referred for concomitant chemoradiation therapy.

SPSS version 23 was used to analyze data. Mean and SD was reported for all continuous variables whereas frequencies and percentages were computed for all qualitative variables. Chi square test was applied to see the difference of outcome among effect modifiers. $\mathrm{P}<0.05$ was taken as statistically significant.

\section{Results}

Total of 100 patients were included in the study. The age of the patients was $41.56 \pm 10.62$ years. The majority of the patients were males $(77 \%$ ) whereas $23 \%$ were females. Most of them were employed (74\%), urdu speaking (58\%) and smokers (70\%) Table 1.

The buccal mucosa was the most common site in 48 patients. About 58 of the tumors were moderately differentiated and 92 patients didn't have family history

Table 1. Socio-Demographic Factors

\begin{tabular}{lc}
\hline Parameter & $\mathrm{n}(\%)$ \\
\hline Age & \\
$<45$ years & $45(45)$ \\
$=>45$ years & $55(55)$ \\
Mean(SD) & $41.56(10.62)$ \\
Gender & $\mathrm{n}(\%)$ \\
Male & $77(77)$ \\
Female & $23(23)$ \\
Occupation & $\mathrm{n}(\%)$ \\
Employed & $74(74)$ \\
Unemployed & $26(26)$ \\
Ethnicity & $\mathrm{n}(\%)$ \\
Sindhi & $26(26)$ \\
Balochi & $8(8)$ \\
Punjabi & $2(2)$ \\
Pushto & $6(6)$ \\
Urdu & $58(58)$ \\
Smoking & $\mathrm{n}(\%)$ \\
Yes & $30(30)$ \\
No & $70(70)$ \\
\hline &
\end{tabular}


Table 2. Clinicopathological Characteristics

\begin{tabular}{lccc}
\hline & $\mathrm{n}(\%)$ & $\mathrm{n}(\%)$ \\
\hline Primary tumor site & $3(3)$ & Clinical Stage & $4(4)$ \\
Lip & Stage 3 & Stage 4 & $96(96)$ \\
Buccal Mucosa & $19(48)$ & Histology & $\mathrm{n}(\%)$ \\
Tongue & $16(16)$ & Well Differentiated & $25(25)$ \\
Nasopharyngeal & $9(9)$ & Moderately differentiated & $58(58)$ \\
Larynx & $5(5)$ & Poorly differentiated & $17(17)$ \\
Hypophyanx & $\mathrm{n}(\%)$ & & \\
Family history of carcinoma & $8(8)$ & & \\
Yes & $92(92)$ & & \\
No & & \\
\hline
\end{tabular}

Table 3. Stratification of Outcome with Respect to Effect Modifiers

\begin{tabular}{|c|c|c|c|c|c|c|}
\hline \multirow[t]{2}{*}{ Variables } & \multicolumn{4}{|c|}{ Outcome } & \multirow[b]{2}{*}{ Total } & \multirow[b]{2}{*}{ P-value } \\
\hline & Complete Response & Partial Response & No Response & Progression & & \\
\hline \multicolumn{7}{|l|}{ Age groups } \\
\hline$<45$ years & 3 & 24 & 2 & 16 & 45 & 0.021 \\
\hline$=>45$ years & 9 & 38 & 2 & 6 & 55 & \\
\hline \multicolumn{7}{|l|}{ Gender } \\
\hline male & 12 & 43 & 1 & 21 & 77 & 0.001 \\
\hline female & 0 & 19 & 3 & 1 & 23 & \\
\hline \multicolumn{7}{|l|}{ Primary diagnosis } \\
\hline Lip & 0 & 0 & 3 & 1 & 4 & \\
\hline Buccal Mucosa & 6 & 28 & 0 & 13 & 47 & \\
\hline Tongue & 0 & 13 & 0 & 6 & 19 & \\
\hline Nasopharyngeal & 3 & 12 & 1 & 0 & 16 & 0.001 \\
\hline Larynx & 3 & 6 & 0 & 0 & 9 & \\
\hline Hypophyanx & 0 & 3 & 0 & 2 & 5 & \\
\hline \multicolumn{7}{|l|}{ Histology } \\
\hline Well Differentiated & 3 & 8 & 3 & 11 & 25 & 0.001 \\
\hline Moderately differentiated & 9 & 38 & 0 & 11 & 58 & \\
\hline Poorly differentiated & 0 & 16 & 1 & 0 & 17 & \\
\hline \multicolumn{7}{|l|}{ Clinical Stage } \\
\hline III & 0 & 4 & 0 & 0 & 4 & 0.466 \\
\hline IV & 12 & 58 & 4 & 22 & 96 & \\
\hline \multicolumn{7}{|l|}{ Treatment } \\
\hline CCRT & 12 & 45 & 3 & 5 & 65 & \\
\hline Surgery & 0 & 17 & 1 & 2 & 20 & 0.001 \\
\hline Best supportive care & 0 & 0 & 0 & 15 & 15 & \\
\hline
\end{tabular}

of cancer. According to stage of cancer, 96 patients were identified in stage IV as shown in Table 2.

Concurrent chemoradiotherapy was performed in majority of the patients (65\%) followed by surgery (20\%) and best supportive care (15\%). The partial response was achieved in majority of the patients after induction chemotherapy with docetaxel and cisplatin regimens (62\%). However 22 patients showed progression of disease, 12 patients achieved complete response and only 4 patients showed stable disease (no response). The most frequent side effects due toxicity of chemotherapy with docetaxel and cisplatin regimens were reported as diarrhea
$(62 \%)$ and neutropenia (57\%).

The outcome i.e. response rate was stratified with respect to age groups, gender, primary diagnosis, histological type, stage and treatment. All the variables showed statistically significant difference $(p<0.05)$ with respect to outcome except stage of tumor Table 3 .

\section{Discussion}

In combination or as a single agent docetaxel is highly active drug for the HNCs. The Phase I trial conducted at Japan showed that endorsed dose of docetaxel was 60 
$\mathrm{mg} / \mathrm{m}^{2}$ and tolerated maximum dose was $70-90 \mathrm{mg} / \mathrm{m}^{2}$ (Kohno, 2005). Docetaxel and cisplatin in combination showed overall response rate as $33-70 \%$ for metastatic and recurrent HNCs (Specht et al., 2000; Glisson et al., 2002; Posner and Lefebvre, 2003; Kohno, 2005). In the current study we have evaluated the role of cisplatin plus docetaxel in the treatment of locally advanced HNCs.

In current study, the mean age of HNC patients was $41.56 \pm 10.62$ years and majority of the patients were of age $\geq 45$ years. In a study author found most of the patients with HNCs were in age group of 41-70 years (Larizadeh et al., 2014). In another study author found majority of the patients were in age group $=>45$ years $(56.8 \%)$ (Akhtar et al., 2016). Hence, age is a potential factor and with increasing age odds of having HNCs also increased as contrast with young individuals. In the current study majority of the HNCs patients were males (77\%). Similar results have been observed in other researches (Bhatia and Jha, 1982; Faggons et al., 2015). In the current study majority of the patients were employed. In a previous study about 239 patients were employed at the time of their diagnosis out of $666 \mathrm{HNCs}$ patients, among them $38.1 \%$ of the patients discontinued their job post therapy due to their malignancy and its treatment (Buckwalter et al., 2007). In our study majority of the patients were urdu speaking (58\%) followed by sindhi $(26 \%)$. A Pakistani study reported the HNCs as the most common cancer in Sindhi males and females ( $8 \%$ and 5\%) (Khaliq et al., 2013). In the current study about $30 \%$ of the patients were smokers. Thus, it has been observed in literature that higher rate of smokers contribute to the incidence of HNCs (Larizadeh et al., 2014).

In the current study majority of the patients had primary site as buccal mucosa $(48 \%)$ followed by tongue $(19 \%)$ and nasopharynx (16\%). However, in 2018 a study conducted found the most common sites as nasopharynx (27.9\%), larynx (20.5\%), sinonasal (12.3\%) and oropharynx (12.3\%) (Adoga et al., 2018). In the retrospective analysis of HNCs conducted at "Shaukat Khanum Memorial Cancer Hospital and Research Center", found oral cavity as the most frequent site (43\%), among them $9.5 \%$ of the cases had buccal mucosa (Faisal et al., 2017). In the current study majority of the HNCs patients had no family history of carcinoma hence another author also showed no association of family history with advanced stage tumor (Adoga et al., 2018). In the present study majority of the patients presented with stage 4 of tumor, similarly in a study conducted by Singh MP et al. found majority of the patients had stage 4 (59.4\%) followed by stage 3 in $32.4 \%$ of the HNCs patients (Singh et al., 2016). We found moderately differentiated histology in most of the patients $(58 \%)$ followed by well (25\%) and poorly differentiated (17\%). Similar findings were revealed by a prveious study, $55 \%$ of the patients had moderately differentiated, $24 \%$ had well and $21 \%$ had poorly differentiated histology of squamous cell carcinoma (Khan et al., 2016).

In our study patients with locally advanced HNCs were given 3 cycles of induction chemotherapy with docetaxel and cisplatin regimens both at a dose of $75 \mathrm{mg} /$ $\mathrm{m}^{2} 3$ weekly. After 3 cycles the CT scan was repeated to assess the clinical response. Majority of the patients achieved partial response after induction of chemotherapy with Docetaxel and Cisplatin (62\%), 22\% patients showed progression of disease, $12 \%$ patients achieved complete response and only $4 \%$ patients showed no response. In previous study, author in their trial of docetaxel and cisplatin included $25 \mathrm{HNCs}$ patients who received 5 treatment cycles ranging from 2 to 8 cycles, $8 \%$ patients showed complete and $25 \%$ showed partial response rate, with overall response rate as $33 \%$. The toxicity was well tolerated and only one patient died due to infection and neutropenia and 3 patients discontinued their treatment due to side effect such as myocardial infraction, massive oedema and persistent thrombocyotopenia (Specht et al., 2000). In the present study, toxicity was also well tolerated and showed adverse events as diarrhea in majority of the patients $(62 \%)$ followed by neutropenia ( $57 \%)$, vomiting (46\%), thromobocytopenia (6\%), anemia (4\%) and fibrile (2\%). A phase II study of weekly docetaxel and cisplatin treatment with concurrent radiotherapy (RT) among 41 patients presented with locally advanced HNCs among them $39.9 \%$ achieved complete response after 1 month of induction chemotherapy, moreover $39 \%$ of the patients showed mucositis followed by neutropenia $(10 \%)$ and dysphagia (5\%) as adverse events due to toxicity (Lee et al., 2017). Another author evaluated the impact of induction chemotherapy with modified dose of docetaxel, cisplatin, plus 5-fluorouracil followed by concurrent chemotherapy in $52 \mathrm{HNCs}$ patients of Asia and achieved partial response in $60 \%$ and complete response in $13.5 \%$ of the individuals after induction chemotherapy, moreover $42.3 \%$ had complete and 25 had partial response rates following radiotherapy and salvage surgery respectively. The most frequently observed adverse events in their study were neutropenia (35\%), stomatitis (35\%), anemia (25\%), diarrhea (16\%), and infections (13.5\%) (Wang et al., 2017).

In our study, the response rate was stratified with respect to age groups, gender, site, histology, stage and treatment. All the variables showed statistical difference $(p<0.05)$ with respect to response rate except stage of tumor. Thirty eight patients had achieved partial response who were age $=>45$ years and only 9 achieved complete response. About 43 male patients achieved partial response and only 19 achieved complete response. Majority of the patients with buccal mucosa as tumor site achieved partial response and only 6 patients achieved complete response. About 38 patients achieved partial response who had moderately differentiated tumor histology, furthermore 58 patients presented with clinical stage 4 achieved partial response. Majority of the patients who had received concurrent chemoradiotherapy (CCRT) achieved partial response in the present study. In a previous study authors found age, gender, treatment group, vomiting, diarrhea and tumor stage as possible potential factors for HNC patients (Zeng et al., 2018). In another research tolerability and effect of induction chemotherapy with weekly docetaxel, cisplatin, and S-1 (weekly TPS) was evaluated which showed $80 \%$ had stage IV disease, while only $20 \%$ had stage III disease, among them $25.7 \%$ achieved complete response and $60 \%$ achieved partial response with overall 
response rate as $86 \%$, however response rates increased post CCRT as $63 \%$ had complete response and $23 \%$ had partial response rate (Bae et al., 2013).

In conclusion, in the present study achievement of partial response was comparatively higher as compared to complete response rate after induction chemotherapy with docetaxel and cisplatin regimens. So it is considered as an effective therapy for the treatment of locally advanced head and neck carcinoma patients and should be suggested for better outcomes.

\section{Ethical Consideration}

Ethical approval was obtained from The Institutional Ethics Committee (No-F.2-81/2018-GENL/Q130/ JPMC). Written informed consent from the participants was obtained by the researcher prior to recruitment. Confidentiality of the participants was maintained at all times. Names of the participants were coded by numbers for the privacy.

\section{Acknowledgements}

I would like to thanks my supervisor and colleagues for the support and guidance throughout the work.

\section{Conflict of Interest}

There was no conflict of interest.

\section{References}

Adelstein D, Gillison ML, Pfister DG, et al (2017). NCCN Guidelines Insights: Head and Neck Cancers, Version 2.2017. J Natl Compr Canc Netw, 15, 761-70.

Adoga AA, Kokong DD, Ma'an ND, et al (2018). The predictive factors of primary head and neck cancer stage at presentation and survival in a developing nation's tertiary hospital. SAGE Open Med, 6, 2050312118792416.

Akhtar A, Hussain I, Talha M, et al (2016). Prevalence and diagnostic of head and neck cancer in Pakistan. PakJ Pharm Sci, 29, 1839-46.

Andresen C, Olson E, Nduaka C, et al (2006). Action of calciotropic hormones on bone metabolism-Role of Vitamin D3 in bone remodeling events. Am J Immunol, 2, 40-51.

Bae WK, Hwang JE, Shim HJ, et al (2013). Multicenter phase II study of weekly docetaxel, cisplatin, and S-1 (TPS) induction chemotherapy for locally advanced squamous cell cancer of the head and neck. BMC Cancer, 13, 102.

Bhatia PL, Jha BK (1982). Pattern of head and neck cancer in Manipur. Indian J Cancer, 19, 241-8.

Boyle P, Levin B (2008). World cancer report 2008, IARC Press, International Agency for Research on Cancer.

Bray F, Ferlay J, Soerjomataram I, et al (2018). Global cancer statistics 2018: GLOBOCAN estimates of incidence and mortality worldwide for 36 cancers in 185 countries. $C A$ Cancer J Clin, 68, 394-424.

Bray F, Ren JS, Masuyer E, et al (2013). Global estimates of cancer prevalence for 27 sites in the adult population in 2008 . Int $J$ Cancer, 132, 1133-45.

Buckwalter AE, Karnell LH, Smith RB, et al (2007). Patient-reported factors associated with discontinuing employment following head and neck cancer treatment. Arch Otolaryngol Head Neck Surg, 133, 464-70.

Catimel G, Verweij J, Mattijssen V, et al (1994). Docetaxel (Taxotere): an active drug for the treatment of patients with advanced squamous cell carcinoma of the head and neck. EORTC Early Clinical Trials Group. Ann Oncol, 5, 533-7.

Colevas AD, Adak S, Amrein PC, et al (2000). A phase II trial of palliative docetaxel plus 5-fluorouracil for squamous-cell cancer of the head and neck. Ann Oncol, 11, 535-9.

Dreyfuss AI, Clark JR, Norris CM, et al (1996). Docetaxel: an active drug for squamous cell carcinoma of the head and neck. J Clin Oncol, 14, 1672-8.

Faggons CE, Mabedi C, Shores CG, et al (2015). Review: Head and neck squamous cell carcinoma in sub-Saharan Africa. Malawi Med J, 27, 79-87.

Faisal M, Malik A, Taqi M, et al (2017). Head and neck cancer in a developing country-a hospital based retrospective study across 10 years from Pakistan. Eur JCancer, 72, S104.

Fung C, Grandis JR (2010). Emerging drugs to treat squamous cell carcinomas of the head and neck. Expert Opin Emerg Drugs, 15, 355-73.

Glisson BS, Murphy BA, Frenette G, et al (2002). Phase II Trial of docetaxel and cisplatin combination chemotherapy in patients with squamous cell carcinoma of the head and neck. J Clin Oncol, 20, 1593-9.

Hashibe M, Brennan P, Chuang SC, et al (2009). Interaction between tobacco and alcohol use and the risk of head and neck cancer: pooled analysis in the International Head and Neck Cancer Epidemiology Consortium. Cancer Epidemiol Biomarkers Prev, 18, 541-50.

Jemal A, Siegel R, Ward E, et al (2007). Cancer statistics, 2007. CA Cancer J Clin, 57, 43-66.

Khaliq SA, Naqvi SB, Fatima A (2013). Retrospective study of cancer types in different ethnic groups and genders at Karachi. Springerplus, 2, 118.

Khan NA, Khan BR, Fatima N, et al (2016). Head and Neck Squamous Cell Carcinoma in a Tertiary Care Hospital. APMC, 10, 203-5.

Kienzer H, Schweiger J, Baur M, et al (1998). Docetaxel (d)/ cisplatin (p) as firstline therapy in head and neck cancer (HNC). Proc Am Soc Clin Oncol, 1998, 1566.

Kohno N (2005). The role of taxanes for head and neck cancer. Gan To Kagaku Ryoho, 32, 2035-9.

Kozakiewicz P, Grzybowska-Szatkowska L (2018). Application of molecular targeted therapies in the treatment of head and neck squamous cell carcinoma. Oncol Lett, 15, 7497-505.

Kozakiewicz P, Grzybowska-Szatkowska L (2018). Application of molecular targeted therapies in the treatment of head and neck squamous cell carcinoma. Oncol Lett, 15, 7497-505.

Lambert R, Sauvaget C, de Camargo Cancela M, et al (2011). Epidemiology of cancer from the oral cavity and oropharynx. Eur J Gastroenterol Hepatol, 23, 633-41.

Larizadeh MH, Damghani MA, Shabani M (2014). Epidemiological characteristics of head and neck cancers in southeast of iran. Iran J Cancer Prev, 7, 80-6.

Lavelle F, Bissery MC, Combeau C, et al (1995). Preclinical evaluation of docetaxel (Taxotere). Semin Oncol, 22, 3-16.

Lee JY, Sun J-M, Oh D, et al (2017). A phase II trial of concurrent chemoradiotherapy with weekly docetaxel plus cisplatin treatment for unresectable locally advanced head and neck cancer. Radiotherapy Oncol, 122, 217-23.

Pignon JP, Bourhis J, Domenge C, et al (2000). Chemotherapy added to locoregional treatment for head and neck squamouscell carcinoma: three meta-analyses of updated individual data. MACH-NC Collaborative Group. Meta-Analysis of Chemotherapy on Head and Neck Cancer. Lancet, 355, 949-55.

Posner MR, Lefebvre JL (2003). Docetaxel induction therapy in locally advanced squamous cell carcinoma of the head and neck. Br J Cancer, 88, 11-7.

Schoffski P, Catimel G, Planting AS, et al (1999). Docetaxel and 
cisplatin: an active regimen in patients with locally advanced, recurrent or metastatic squamous cell carcinoma of the head and neck. Results of a phase II study of the EORTC Early Clinical Studies Group. Ann Oncol, 10, 119-22.

Singh MP, Kumar V, Agarwal A, et al (2016). Clinico-epidemiological study of oral squamous cell carcinoma: A tertiary care centre study in North India. J Oral Biol Craniofac Res, 6, 31-4.

Specht L, Larsen SK, Hansen HS (2000). Phase II study of docetaxel and cisplatin in patients with recurrent or disseminated squamous-cell carcinoma of the head and neck. Ann Oncol, 11, 845-9.

Tubiana-Mathieu N, Genet D, Cupissol D, et al (2000). Final results of phase II study of patients (pts) with metastatic or recurrent squamous cell carcinoma of the head and neck (SCCHN) treated with docetaxel (D) and 5-fluorouracil (5-FU). Proc Am Soc Clin Oncol, 2000, 1656.

Wang HM, Lin CY, Hsieh CH, et al (2017). Induction chemotherapy with dose-modified docetaxel, cisplatin, and 5-fluorouracil in Asian patients with borderline resectable or unresectable head and neck cancer. J Formos Med Assoc, 116, 185-92.

Zeng Z, Yan R-N, Tu L, et al (2018). Assessment of concurrent chemoradiotherapy plus induction chemotherapy in advanced nasopharyngeal carcinoma: Cisplatin, fluorouracil, and docetaxel versus gemcitabine and cisplatin. Sci Rep, $\mathbf{8}, 15581$.

This work is licensed under a Creative Commons AttributionNon Commercial 4.0 International License. 